\author{
ZBYSZKO MELOSIK \\ Uniwersytet im. Adama Mickiewicza \\ $w$ Poznaniu
}

\title{
SAMOCHÓD, TOŻSAMOŚĆ I PŁEĆ KULTUROWA
}

\begin{abstract}
Melosik Zbyszko, Samochód, tożsamość i płeć kulturowa [Car, Identity and Gender]. Studia Edukacyjne nr 36, 2015, Poznań 2015, pp. 73-86. Adam Mickiewicz University Press. ISBN 978-83232-2958-2. ISSN 1233-6688. DOI: 10.14746/se.2015.36.5
\end{abstract}

My article is devoted to selected contexts of the car as a sociological phenomena, primarily in the context of the constructions of gender. I am convinced that the car is not only a product of modern technology; it is connected with meanings and symbols of the socio-cultural reality. It is a symbol of freedom, autonomy, individualism and privacy. From the very beginning of its existence, the car was seen as an integral part of male identity and the "car culture" was seen as definitely masculine. However, in the first decades of the twentieth century women driving cars have become a powerful symbol of gender equality. The author discusses these problems in the context of contemporary culture.

Key words: car, identity, masculinity, femininity, gender

Samochód stanowi nie tylko wytwór nowoczesnych technologii; jest przesycony znaczeniami i symbolami społeczno-kulturowymi. W poniższych rozważaniach odniosę się do kilku wybranych kontekstów jego usytuowania - związanych przede wszystkim z konstrukcjami płci kulturowej.

Wyjdę od eksponowanego przez Amy L. Best twierdzenia, że "samochody są kluczowym symbolem wertykalnej i horyzontalnej ruchliwości", zmieniają nasze relacje wobec przestrzeni i czasu'1. Tworzą wręcz odczucie panowania nad nimi. Amerykanie uważają, że samochód pozwala im dotrzeć do „nieznanych miejsc, jak również przekraczać granice, tak jak to było

${ }^{1}$ L.A. Best, Fast Cars, Cool Rides: the Accelerating World of Youth And Their Cars, New York 2006, s. 14. 
kiedyś, nawet jeśli jadą oni jedynie do supermarketu"2. Nazwy wersji marek, takie, jak „Wyprawa”, „Odkrywca”, czy „Mustang” mają wyrażać przekonanie, że "jest możliwe inne życie za zakrętem drogi, na horyzoncie czy w jakimś dalszym egzotycznym miejscu" 3 .

Samochód jest też symbolem wolności, prywatności i autonomii ${ }^{4}$. Kierowca ma przy tym często wrażenie (aż do momentu kiedy nie zostanie zatrzymany przez patrol policyjny), że przynajmniej na autostradach uwalnia się spod kontroli społeczeństwa. W tym kontekście paradoksalnie on i technologiczny z istoty swojej samochód stają się niejako częścią natury.

Bez wątpienia, samochód jest też częścią społecznego systemu statusów społecznych, sygnalizuje miejsce na drabinie społecznej. W świadomości społecznej istnieje przy tym hierarchia samochodów, a właściwie ich marek, która przekłada się na hierarchię ich właścicieli. Można nawet stwierdzić, że klasa samochodu stanowi widomy dowód przynależności właściciela do określonej klasy społecznej. Warto dodać, że - jak pisze David Gartman w pierwszej fazie swojego istnienia (jeszcze w końcu XIX wieku) „piękne drogie wehikuły były używane częściej nie dla praktycznego transportu, a dla aktywności wypoczynkowych i publicznej ostentacji"; "stały się one podstawowym akcesorium klasy próżniaczej, która używała ich do turystyki, wyścigów i paradowania poprzez modne bulwary ${ }^{5}$.

Trudno więc nie zgodzić się z tezą L.A. Best, iż „samochody służą często jako wskaźniki społecznej i ekonomicznej wartości [człowieka], jak również jako kluczowe wyznaczniki tożsamości"6. Samochód symbolizuje też władzę i agresję. Joseph J. Tobin podaje, że japońscy gangsterzy używali zawsze drogich, symbolizujących władzę i bogactwo samochodów: w latach sześćdziesiątych - Cadillaca, w siedemdziesiątych był to Lincoln-Continental, w latach osiemdziesiątych - Mercedes-Benz, a w dziewięćdziesiątych Lamborghini $^{7}$ (w jednej z reklam Dodge Nitro stwierdzano, że jest on „wysokiej jakości pojazdem z wyglądem zabójcy"8).

2 D. Lipset, Introduction. Charon's Boat and Other Vehicels of Moral Imagination, [w:] Vehicles: Cars, Canoes and other Metaphors of Moral Imagination, red. D. Lipset, R. Handler, New YorkOxford 2014, s. 9.

3 Tamże, s. 9.

4 Tamże, s. 8.

${ }^{5}$ D. Gartman, Three Ages of Automobile. The Cultural Logics of Car, Theory, Culture and Society, 2004, 21, 69, s. 170.

${ }^{6}$ L.A. Best, Fast Cars, Cool Rides, s. 4.

7 J.J. Tobin, Re-Made in Japan. Everyday Life and Consumer Taste in a Changing Society, New Haven 1992, s. 35-36.

8 S. Redshaw, In the Company of Cars. Driving as a Social and Cultural Practice, HampshireBurlington 2008, s. 41. 
Od samego początku swojego istnienia samochód postrzegany był jako integralny element męskiej tożsamości, a „kultura samochodu” była postrzegana jako zdecydowanie zmaskulinizowana. Uważano, że miejsce kobiety jest na fotelu pasażera, a nie za kierownicą. To mężczyzna miał kontrolować nową technologię . Jednocześnie przy tym identyfikowano kompetencje w zakresie kierowania samochodem z kompetencjami, które „z natury” swojej posiada mężczyzna10. W latach 1914-1918, kiedy to wiele kobiet uzyskało prawo jazdy, pojawiła się w krajach zachodnich obawa przed „feminizacją samochodu"11. Samochód postrzegany był jako „część świata męskiego języka inżynierów”12. Uważano, że „nerwowość” kobiety nie pozwala jej na sprostanie tak precyzyjnemu zadaniu, jakim jest kierowanie samochodem ${ }^{13}$.

W jednym $\mathrm{z}$ tekstów z końca trzeciej dekady XX wieku wyróżniono $\mathrm{w}$ kontekście kierowania samochodem - trzy typy neurotycznych kobiet. Pierwszy z nich, to "agresywna kobieta za kierownicą", która "chce potwierdzić, że jest tak dobra jak mężczyzna”. Drugi typ to kobieta "bezradna za kierownicą", szczególnie w każdej sytuacji, która wymaga szybkiej decyzji i precyzyjnego działania. Wreszcie, trzeci typ związany jest z kierowaniem przez kobiety „z tylnego siedzenia”, nie bezpośrednio, lecz poprzez histeryczne, pełne paniki komentarze ${ }^{14}$. $\mathrm{Z}$ kolei, w reklamach samochodów z lat dwudziestych i trzydziestych piękna i dobrze ubrana kobieta pełniła rolę dekoracyjną i pasywną, a jej obecność miała zwiększyć wartość konsumpcyjną samochodu dla mężczyzn ${ }^{15}$. W tym kontekście mężczyzna ma „podwójną wartość do opanowania" - kobietę i samochód.

Również i obecnie atrakcyjne kobiety mają zwiększać atrakcyjność reklam samochodów, jak i innych produktów. Przy tym samochód jest niekiedy w tych reklamach traktowany instrumentalnie - jako „wartość dodana” do innego towaru. Mogę podać w tym miejscu bardzo szokujący przekaz tego typu, którego bohaterką jest celebrytka Paris Hilton. Oto w pierwszej, zajmującej 2/3 czasu części emitowanej w maju 2005 roku reklamie burgerów Carl's Jr. (sieci, która działa głównie w Stanach Zjednoczonych), półnaga Paris Hilton w seksualnej ekstazie myje gąbką luksusowy czarny samochód, wijąc się na jego masce, obtaczając pianą sama siebie, odbywając

${ }^{9}$ S. O'Connell, The Car and British Society: Class, Gender and Motoring, 1896-1939, s. 5.

10 Tamże, s. 43.

11 Tamże, s. 44.

12 Tamże, s. 45.

13 Tamże, s. 46.

14 Por. tamże, s. 57.

${ }_{15}$ M. Walsh, Gender and Automoblity. Selling Cars to American Women after the Second World War, "Charm" 2009, http://learn.quinnipiac.edu/charm/CHARM\%20proceedings/CHARM \%20article\%20archive\%20pdf\%20format/Volume\%2014\%202009/walsh.pdf, s. 296-297. 
niemalże z tym samochodem stosunek seksualny. W ostatniej części reklamy Paris Hilton wgryza się w ogromnego hamburgera, jedząc go w pianie, klęcząc obok samochodu, wykonując świadomie wyuzdane ruchy ciałem, a w szczególności pośladkami. Następnie, nadal w ekstazie, wodą z węża zmywa samochód. Reklama burgera stanowi tu bez wątpienia formę "miękkiej pornografii” 16 . W komentarzu czasopisma „A Hamburger Today”, poświęconego sztuce kulinarnej tej potrawy, zacytowano wypowiedź jednego z szefów marketingu burgerów Carl's Jr.: „Przekaz [w reklamie] jest bardzo prosty - Paris, sytuacja i spicy BBQ [ostro przyprawiony grillowany burger] (...) są <pikantne>. Paris została wybrana, aby być gwiazdą tej reklamy, ponieważ jest ona intrygującą ikoną kulturową i jest <tą właśnie> dziewczyną - absolutną atrakcją („it girl”). Ona fascynuje najbardziej lojalnych klientów Carl's Jr., czyli <młodych głodnych facetów $>$ i $<$ młode głodne dziewczyny $>$ "17.

Męski odbiorca tej reklamy otrzymuje przekaz, łączący konsumpcję hamburgerów z posiadaniem luksusowych samochodów oraz seksualnym podbojem uprzedmiotowionych kobiet. Takie podejście wpisuje się znakomicie w pogląd, który głoszą Peter S. Freund i George T. Martin, iż „wartości kulturowe automobilizmu znajdują swoją psychiczną analogię w męskiej psychologii panowania i kontroli, która włącza kulturę szybkości, władzy i podboju natury"18.

Jak już wspomniano, wspaniały samochód stanowi zarówno symbol męskości samej $\mathrm{w}$ sobie, jak i symbol męskiego sukcesu. Trzeba dodać, że w reklamach luksusowych produktów mężczyźni sukcesu portretowani są samotnie lub $\mathrm{w}$ towarzystwie innych mężczyzn sukcesu (taki przekaz zawarty jest $\mathrm{w}$ jednej z publikowanych w Polsce reklam mody męskiej Pierre'a Cardina; tłem dla modeli są tam przy tym eleganckie samochody i szybowce). Mężczyźni sukcesu nie zawsze przy tym mają czas dla kobiet (jeśli już kobieta pojawia się $\mathrm{w}$ przekazie, to po to, aby podziwiać męski sukces). Zawsze mają jednak czas dla swoich samochodów. W kulturze Zachodu (a szczególnie w jej wersji amerykańskiej) samochody zawsze związane były z podkreślaniem klasowo-kulturowej identyfikacji. Służyły przy tym jako ważny środek ekspresji mężczyzny - ukazywały jego „siłę i smak”. Jak pisze John Fiske, „kiedy mężczyzna ma pieniądze, kupuje najlepszy samochód, na

16 Por. reklama, adres internetowy, http:/ / www.youtube.com/watch?v=OsxYRJQWc0k, [dostęp: 3.09.2013].

17 Por. Hot' $n$ ' Spicy: Paris Hilton's Burger Commercial for Carl's Jr., „A Hamburger Today", May 17, 2005, adres internetowy: http://aht.seriouseats.com/archives/2005/05/hot-nspicy.html; [dostęp: 3.09.2013].

18 Podaję za: S. Redshaw, In the Company of Cars, s. 5. 
jaki może sobie pozwolić". Również i dzisiaj samochody są znakami tożsamości; stanowią nadal jeden $\mathrm{z}$ ważniejszych, widocznych na co dzień wyróżników sukcesu19 (jak napisano na jednym z polskich plakatów reklamowych: „przedstawiając swój stan posiadania wymieniasz najpierw markę ukochanego samochodu, a potem imię ukochanej kobiety"). W reklamach drogich samochodów, takich jak na przykład Lexus pokazuje się też mężczyznę - potencjalnego kierowcę - jako osobę racjonalnego, niezależnego indywidualistę, posiadającego kontrolę nad własnym życiem ${ }^{20}$. Są one przesycone takimi kluczowymi pojęciami, jak władza, precyzja, osiągnięcia. Samochód człowieka sukcesu musi „robić dobre wrażenie” i (przynajmniej potencjalnie) połykać przestrzeń szybciej niż samochody innych mężczyzn. Większość kierowców na amerykańskich reklamach to młodzi biali mężczyźni, samowystarczalni samotnicy. Są oni upodmiotowieni przez samochód, który pozwala im na transcendencję codziennej egzystencji. Niekiedy samochód prezentowany jest jako kobieta; reaguje on przy tym na dotyk i wolę męskich dłoni bardziej czule niż ona. Wówczas, jak żadne z innych dóbr materialnych, samochód reprezentuje „świat patriarchalnego porząd$\mathrm{ku}^{\prime 21}$. Według Andrewa Wernicka, do symboliki patriarchii odwołują się wszystkie rodzaje reklam samochodów. Samochód wyścigowy symbolizuje rytuał męskiego współzawodnictwa i przejaw doskonałości „męskiej technologii". Samochód luksusowy to oznaka abstrakcyjnej tradycji i statusu. W polskiej reklamie Jaguara w wersji Majestic napisano: „Niezwykły urok luksusowego wnętrza Jaguara $\mathrm{w}$ wersji Majestic harmonizuje $\mathrm{z}$ pięknem jego klasycznej, doskonałej w proporcjach sylwetki. To reprezentacyjna limuzyna, która otacza pasażerów aurą prestiżu, komfortu i wykwintnej elegancji". Wreszcie samochód rodzinny (ruchomy dom), godny szacunku, funkcjonalny i bezpieczny jest uosobieniem ideału nuklearnej rodziny, której głową jest mężczyzna sukcesu22.

Z kolei, jak twierdzą Boonghee Yoo i Seung-Hee Lee - na przykład dla rywalizujących o eksponowanie swojej pozycji menedżerów wyższego szczebla - drogie samochody niekiedy są kupowane przede wszystkim dlatego, aby ostentacyjnie bawić się ich kluczykami podczas rozmów z kolegami i zebrań $\mathrm{w}$ firmie. $\mathrm{W}$ tym drugim przypadku potwierdza się teza, że dla

${ }^{19}$ A. Wernick, Vehicles for Myth: The Shisfting Image of the Modern Car, [w:] Cultural Politics in Contemporary America, red. I. Angus, S. Jhally, New York 1989, s. 202; J. Fiske, Reading the Popular, London 1994, s. 23.

${ }^{20}$ J.E. Schroeder, D. Zwick, Mirrors of masculinity: Representation and identity in advertising images, Consumption Markets \& Culture, 2004, 7.1, s. 40.

${ }^{21}$ Por. D. Barthel, When Men Put on Appearances. Advertising and the Social Construction of Masculinity, [w:] Man, Masculinity and Media, red. S. Craig, Sage 1992, s. 141.

22 A. Wernick, Vehicles for Myth, s. 203. 
„wielu ludzi głównym celem posiadania dobra materialnego jest wywieranie wrażenia na innych, a nie na sobie"; istotą jest tutaj zawsze „zewnętrzna fizyczna próżność", ,efekt wystawiania na pokaz"23.

Warto w tym miejscu podać przykład kulturowej adaptacji luksusowych samochodów - na przykładzie Chin. Generalnie, orientacja na luksus pozostaje w sprzeczności z tymi - ciągle jeszcze obowiązującymi w społeczeństwie chińskim - konfucjańskimi wartościami i cechami tożsamości, jakimi są skromność i pokora. To one, w powszechnym przekonaniu, stanowią podstawę utrzymania „stabilności społecznej”24. Ponadto, tradycyjnie ceni się tam oszczędność, z którą orientacja na luksus pozostaje $\mathrm{w}$ zasadniczej sprzeczności ${ }^{25}$, podobnie jak $\mathrm{z}$ tą tradycyjną wartością, jaką jest kolektywizm i harmonia grupowa oraz brak konkurowania w sferze posiadania dóbr ${ }^{26}$. W jaki sposób postępują w związku z tym chińscy superbogacze? (którzy zwyczajowo „wybierają jedynie spośród słynnych marek i nie chcą podejmować ryzyka wydania dużej sumy pieniędzy na marki nieznane, nawet jeśli mają one międzynarodowy prestiż" ${ }^{27}$ ). Przede wszystkim, jak twierdzi Pierre Xiao Lu, luksusowe marki są kupowane bardzo dyskretnie, a ich "wykorzystanie jest prywatne i osobiste, a nie ostentacyjnie publiczne". Podaje on przykład stosunku najbogatszych Chińczyków do drogich samochodów - niekiedy rezygnują oni z zakupu spektakularnego Rolls-Royce'a na rzecz Bentleya: „Logo latającej damy [Rolls-Royce'a] wydaje się być zbyt ostentacyjne dla superbogatych Chińczyków, symbolizując ekstremalną władzę porównywalną do tej, którą posiadają cesarze i królowie: w socjalistycznych Chinach nikt nie chce zakwestionować rządów partii komunistycznej. Relatywna dyskrecja i skromność Bentleya bardziej odpowiada mentalności chińskich super-bogaczy"28. Dodam, iż ceny samochodów Bentleya w ofercie na rok 2013 sięgały 200 tysięcy dolarów (np. „Bentley Continental Flying Spur”), czy niemalże 300 tysięcy dolarów (np. „Bentley Continental Supersports") 29 .

W celu weryfikacji sposobu reklamowania towarów luksusowych we współczesnych Chinach, podjąłem próbę krótkiej analizy reklam bardzo dobrych samochodów. Pierwszy z nich to samochód Byd F6, produkcji chiń-

${ }_{23}$ B. Yoo, S.-H. Lee, Buy Genuine Luxury Fashion Products or Counterfeits? Advances in Counsumer Research, 2009, 36, s. 282.

${ }^{24}$ P. Xiao Lu, Elite China: luxury consumer behavior in China, 2011, s. 50.

25 Tamże, s. 51.

26 Tamże, s. 53.

27 Tamże, s. 76.

28 Tamże, s. 51.

${ }^{29}$ Por. AutoGuide. com, 2013 Bentley Cars, http://www.autoguide.com/new-cars/ bentley, [dostęp: 21.06.2013]. 
skiej (cena w złotówkach około 140 tysięcy). Bohaterem krótkiej reklamy jest samochód "sam w sobie" - ani przez moment nie pojawia się na nim człowiek. Samochód prezentowany jest jako majestatyczny symbol powagi i nawet władzy (reklamie towarzyszy, nie mająca nic wspólnego z kulturą chińską, chóralna, równie majestatyczna muzyka). Jednakże zdaje się funkcjonować poza społeczeństwem, zdaje się być dobrem luksusowym, które do nikogo nie należy, jedynie "do siebie samego" - jest sam dla siebie jedynym układem odniesienia. $Z$ ogromnego sterylnego luksusowego zamkniętego placu wyjeżdża na autostradę, kierując sobą samym i potem przed moment widać na reklamie coś więcej niż tylko technologię - fragment lasu i rzekę ${ }^{30}$. Nieco inny charakter ma chińska reklama absolutnie luksusowego Mercedesa E300L. I tym razem akcja reklamy rozgrywa się jakby poza społeczeństwem, chociaż występują w niej dwie osoby. Młody chiński businessman lub urzędnik bardzo wysokiego szczebla wsiada nocą do mercedesa stojącego przed bardzo okazałym rozświetlonym budynkiem, przed którym na postumentach spoczywają dwa chińskie lwy. Trzeba dodać, że $\mathrm{w}$ tradycji chińskiej lew umieszczany był przed budynkami państwowymi i świątyniami oraz przed rezydencjami najwyższych oficjeli i przed tronem cesarza. Był symbolem dostojeństwa i potęgi, mądrości, szczęścia i dostatku. Jednocześnie wierzono, że chroni przed złymi mocami i duchami ${ }^{31}$. Prowadzony przez kierowcę mercedes mknie ulicami pustego miasta, a ożywione lwy pędzą wokół niego, "pilotując” go niejako i dając ochronę. Samochód zatrzymuje się przed okazałą rezydencją, właściciel samochodu wychodzi z niego i z pełnym władzy wyrazem twarzy nakazuje lwom zająć miejsce na postumentach, tym razem przed jego miejscem zamieszkania. Mercedes jest tu więc symbolem władzy i potęgi oraz dobrobytu, choć unika się „wynoszenia” jego właściciela ponad resztę społeczeństwa. I w tym przypadku żyje on jak gdyby "sam w sobie" wraz ze swoim samochodem.

Jazdę samochodem można także, bez wątpienia, wpisać w powszechną wśród młodych mężczyzn „kulturę ryzyka”. Oto bowiem w kulturze współczesnej występuje społecznie skonstruowana obawa przed monotonnym życiem. W dominujących przekazach medialnych młodzi ludzie są przekonani, że ich codziennym obowiązkiem jest nie tylko konieczność wspinania się pod drabinie społecznego sukcesu, ale także "natychmiastowa przyjemność" oraz - co interesuje mnie w tym kontekście najbardziej - maksymalizacja wrażeń. Ma się wrażenie, że życie ma być niczym film sensacyjny.

30 Byd F6 commercial ad Cinese Car, spot reklamowy, http://www.youtube.com/ watch?v=1cij9LPNas0, [dostęp: 21.06.2013].

${ }^{31} \mathrm{Na}$ temat symboli lwów chińskich por. M.B. Duda, Traditional Chinese Toggles. Counterweights and Charms, Singapour 2011, s. 108-111. 
Młodzi ludzie nie chcą więc zadowolić się "zwykłymi tradycyjnymi przyjemnościami". Pragną nadzwyczajnych wydarzeń i ekstremalnych przeżyć (może po to, aby w życiu wcielić się $\mathrm{w}$ rolę swojego ulubionego komputerowego bohatera, który nie ma chwili spokoju). Nie ulega wątpliwości, że idea „maksymalizacji wrażeń" jest nieodłączną częścią społeczeństwa konsumpcji: ekscytacja i ryzyko „nakręcają konsumpcję”, są dobrze sprzedającym się towarem. Ludzie szukają więc sposobów na "skok adrenaliny" i gonią za ekstremalnymi doznaniami (symbolem takiego stylu życia może być kierowanie bolidem $\mathrm{w}$ wyścigach Formuły I lub sporty ekstremalne). Większość z nich stoi jednak - w obliczu ideologii skoku adrenaliny - przed trudnym zadaniem. Niewielu ma takie kompetencje osobowościowe i fizyczne, które pozwalają na „wejście w realną eXtremalność”. Nie są dość sprawni fizycznie lub nie mają odwagi, aby zdobywać Czomolungmę (ani nawet Czerwone Wierchy), aby opłynąć jachtem świat dookoła (a nawet aby wypłynąć nim na środek najbliższego jeziora)... Nie mają tyle samozaparcia, aby poświęcić swój czas i wysiłek na zdobycie kompetencji taternika, skoczka spadochronowego... Nie mają siły, aby pokonać swoje obawy i lęki. Cóż więc pozostaje? Część z nich rezygnuje z przeżywania ekstremalności w realnym świecie i „preparuje ją we własnym mózgu”. Sięgają więc po środki chemiczne, które przesuwają "granicę ekstremalności” do granic „życia i śmierci". Znakomitym przykładem są w tym kontekście narkotyki, jako (ekstremalnie) najprostsza "droga na skróty". Dostarczają one różnego typu destrukcyjnej $\mathrm{w}$ swoich konsekwencjach ekstazy w pigułce, bez wysiłku intelektualnego i fizycznego (stanowiąc logiczne pogłębienie doznań, które oferują twórcy reklam drinków energetycznych). Pozytywna odpowiedź na prowadzoną $\mathrm{w}$ społeczeństwie konsumpcji "politykę ekstazy" (pojęcie to świadomie nawiązuje do nazwy jednego z narkotyków), której przekaz jest bardzo jasny: szukaj ekscytacji i ryzyka.

Dla innych młodych ludzi poszukiwanie ekstremalnych doznań zostaje zredukowane do ekstremalnie niebezpiecznej jazdy samochodem (wyprzedzanie "na trzeciego na zakręcie”), która przekształca się w swoistą formę rosyjskiej ruletki. Robert W. Connell uznaje nawet taką jazdę za jedną z podstawowych form stosowania przez mężczyzn przemocy, stawiając ją $\mathrm{w}$ jednym szeregu z przemocą domową i gwałtami, mobbingiem $\mathrm{w}$ pracy, zachowaniami homofobicznymi, czy nieuzasadnionym używaniem broni palnej32. Jak wykazały badania, w jednej z australijskich grup młodzieży

32 R.W. Connell, Arms and the man: using the new research on masculinity to understand violence and promote peace in the contemporary world, [w:] Male roles, masculinities and violence: A culture of peace perspective, red. I. Breines, R. Connell, I. Eide, Paris 2000, May, s. 31-32. 
jazda pod wpływem alkoholu stanowi wyraz ekspresji męskości33. Z kolei, w jednym $z$ raportów dotyczących mężczyzn afrykańskich uznano, iż palenie papierosów, nadużywanie alkoholu oraz niebezpieczna jazda samochodem stanowią formę wyrażania patriarchalnej władzy ${ }^{34}$. Można podsumować, że niebezpieczna jazda "stanowi fenomen społeczny; przekraczanie szybkości (...) wynika z dążenia do pokazania się przed innymi, w stosunku do innych kierowców, widowni na zewnątrz lub wewnątrz samochodu", zwycięstwo lub porażka $\mathrm{w}$ niekiedy bardzo przypadkowych drogowych wyścigach postrzegane jest przez mężczyzn bardzo poważnie ${ }^{35}$. Społeczne konstrukcje męskości $\mathrm{w}$ kontekście zachowania się na drodze wynikają z nakładania się na siebie takich kategorii, jak honor i zwycięstwo, a z drugiej strony - upokorzenie i wstyd ${ }^{36}$.

Warto dodać, że kultura drogi jest „demokratyczna”, w tym znaczeniu, w rywalizacji o miejsce na niej i prowadzonych różnego typu nieformalnych wyścigach, gdzie zarówno status właściciela samochodu, jak i jego marka nie odgrywa żadnej roli (choć trzeba brać pod uwagę możliwości pojazdu wyrażone przez jego parametry techniczne). W nieformalnych wyścigach na drodze główną rolę odgrywa odwaga i skłonność do podjęcia ryzyka (i narażenia siebie oraz innych na niebezpieczeństwo czy nawet śmierć). Szybka jazda samochodem może być formą kompensacji niskiego statusu społecznego kierowcy, który - dzięki swoim umiejętnościom w zakresie kierowania i brawurze - wyprzedza luksusowe samochody symbolizujące wysoką przynależność klasową ich właściciela. I w tej właśnie perspektywie należy umieścić pogląd Theodora Adorno, iż samochód daje osobom należącym do różnych klas społecznych identyczne iluzje - odnoszące się do kompensacji stosunków klasowych w procesie produkcji ${ }^{37}$.

Niekiedy też szybka jazda samochodem oraz wyprzedzanie na drodze może być związane $\mathrm{z}$ niepowodzeniami $\mathrm{w}$ innych sferach życia. Warto w tym miejscu przywołać wysuniętą przez R. Willera tezę o „męskiej hiperkompensacji poczucia niższości, co prowadzi do podejmowania przez mężczyzn odczuwających zagrożenie dla swojej męskości zachowań typowych

33 R.W. Connell, J.W. Messerschmidt, Hegemonic Masculinity. Tethinking the Concept, Gender \& Society, 2005, 19.6, s. 838.

${ }^{34} \mathrm{O}$. Miruka, A Training Manual of Masculinities and Engaging Men. To End Gender Based Violence, 2013, https://ke.boell.org/sites/default/files/training_manual_on_masculinities_and_ engaging_men.pdf, s. 65.

${ }^{35}$ D. Balkmar, Drive-by Shaming Reflections on the Emotions of (Dangerous) Car Driving, [w:] Thinking with Beverely Skeggs, red. A. Olsson, Stockholm 2008, http://www.erg.su.se/ polopoly_fs/1.39103.1320403015!/Thinking_with_Beverley_Skeggs.pdf, s. 10.

36 Tamże, s. 18.

37 D. Gartman, Three Ages of Automobile. 
dla ekstremalnych form męskości" - w tym przypadku pokazywania odwagi i wystawiania się na niebezpieczeństwo ${ }^{38}$. Wiele badań wykazuje, że u części mężczyzn występuje silny związek między „identyfikacją z osobowością typu <macho> a agresywnym zachowaniem podczas jazdy samochodem"39. W społecznym postrzeganiu istnieje przy tym wzajemna, wzmacniająca się relacja między męskością kierowcy a męskością jego samochodu. Aparycja i możliwości techniczne samochodu konstytuują jego męskość, jednakże jego cechy charakteru i sposób kierowania mogą potwierdzać męskość jego samochodu.

Samochód stanowi także źródło poczucia własnego indywidualizmu co jest paradoksalne w kontekście bardzo precyzyjnie określonych regulacji prawnych odnoszących się do zasad ruchu drogowego oraz skrajnie zrutynizowanej techniki prowadzenia (kierownica, biegi, pedał gazu itp. $)^{40}$. To poczucie indywidualizmu związane jest $\mathrm{z}$ istnieniem $\mathrm{w}$ umyśle kierowcy subiektywnego poczucia możliwości wyboru drogi, szybkości jazdy, a także bez wątpienia samej „radości szosy” - pędu i poczucia wręcz organicznego związku między kierującym, samochodem a "połykaną przestrzenią" (w tym kontekście całkowicie odmienny charakter ma samolot, w którym jednostka łatwo może czuć się bezwolna i zależna). Drugi kontekst indywidualizmu związany jest $\mathrm{z}$ wyborem marki i typu samochodu - przy zakupie oraz inscenizowaniem różnicy i personalizacji. Oto bowiem we współczesnym społeczeństwie konsumpcji nie mamy już do czynienia $\mathrm{z}$ homogenizacją populacji, lecz działaniem poprzez różnicowanie jednostek, choć zawsze w ramach już istniejącego hiperprogramu wyborów w zakresie stylu życia i konsumpcji. Ludzie są przekonani, że mają wolność (re)konstrukcji swojego stylu życia i tożsamości. Nie zdają sobie sprawy, iż poruszają się w ramach kafeterii (setek) tysięcy wyborów zaprojektowanych w ramach owego hiperprogramu. Współcześnie różnica konstruowana jest $\mathrm{w}$ dużej mierze „na zewnątrz" człowieka, głównie poprzez różnorodne produkty kulturowo-tożsamościowe. Do przeszłości zdaje się natomiast odchodzić ten rodzaj różnicy tożsamościowej, który związany jest z budowaniem swojej odmienności (i odrębności od świata) przez wiele dekad życia - poprzez „wyrabianie w sobie” cech wewnętrznych, kształtowanie „woli i charakteru”, czy

${ }^{38}$ H. McLaughlin, Ch. Uggen, A. Blackstone, Sexual Harassment, Workplace Authority, and the Paradox of Power, American Sociological Review, August 2012, 77, 4 https://www. soc.umn.edu/ uggen/McLaughlin_Uggen_Blackstone_ASR_12.pdf, s. 3, spr strony

${ }^{39}$ M. Schmid Mast i in., Masculinity causes speeding in young men, Accident Analysis and Prevention, 2008, 40, s. 840.

40 Por. też krytyczne uwagi na temat wpływu samochodu na dyscyplinowanie ciała i tożsamości kierowcy: J. Urry, Życie za kótkiem, [w:] Socjologia codzienności, red. P. Sztompka, M. Bogunia-Borowska, Kraków 2008. 
określonych kompetencji (różnica jest wówczas ukryta głęboko w tożsamości, a człowiek jest odmienny wewnętrznie).

Tak więc, w kulturze współczesnej idea „musisz być taki sam” ustąpiła miejsca idei „musisz być odmienny”. Powtórzę raz jeszcze, we współczesnym społeczeństwie konsumpcji dominuje zainscenizowana różnica człowiek definiowany jest przez symulowaną odmienność od innych. Jej źródłem jest wybór konsumencki ${ }^{41}$. Jednocześnie, obecnie wolność jest zredukowana $\mathrm{w}$ świadomości setek milionów osób do wolności konsumpcji. Sukces, który osiągnął korporacyjny rynek $\mathrm{w}$ narzuceniu ideologicznie skonstruowanej wolności - jako wolności do konsumpcji - powoduje, że ludzie rzeczywiście czują się wolni mając możliwość wyboru między setkami typów telewizorów, produktów żywnościowych (serków brie?), czy sposobów spędzania wolnego czasu. Ogromne, subiektywne poczucie wolności daje możliwość spędzenia wakacji w Chorwacji, na Jamajce, w Tajlandii czy Egipcie - a wybór taki jest dostępny dla wielu milionów. Ludzie postrzegają swoje życie nie z perspektywy własnego rozwoju wewnętrznego, własnej „autentyczności” czy podmiotowości, a w kontekście oferty, jaką otrzymują - niezwykle bogatej, lecz zawsze w ramach obowiązujących wzorów konsumpcji. Wydaje się im, że kreują własne życie, a oni tylko „wybierają z oferty". Uważają, że mają tym więcej wolności, w im większym stopniu (i w im bardziej spersonalizowany sposób) mogą urzeczywistnić swój osobisty potencjał $\mathrm{w}$ zakresie konsumpcyjnych wyborów. W ramach poszczególnych sektorów konsumpcji budowane są przy tym całe przestrzenie wolności i indywidualizmu, których samochód jest znakomitym przykładem, na przykład: Toyota, Mercedes, Volvo, Porsche, Citroen, Fiat, Alfa Romeo, Lambhorgini, Cadillac, Peguet, Renault, Mitshubishi, Rolls-Royce, Audi, Mazda, Nissan, Honda, Suzuki, Subaru, Seat, Chrysler, Land Rover, Dacia, Jaguar, Skoda, Opel, BMW, Lancia, Bentley, Kia, Volkswagen, Pontiac, Daihatsu, Ford. A jeśli już na przykład zdecydujemy się urzeczywistnić swoją wolność poprzez wybór tego ostatniego samochodu z wymienionej listy, to otwiera się przed nami kolejny świat fascynującej wolności, związana z możliwościami wyboru z różnego typu odmian tej marki: KA, Fiesta, Fiesta ST, B-Max, C-Max, Focus ST, Focus RS, Kuga, Mondeo, Mondeo Vignale, Mustang, S-Max, Galaxy, Tourneo Courier, Tourneo Connect, Tourneo $\mathrm{Cu}-$ stom. Jeśli już zdecydujemy się na jeden z tych wariantów, to stoimy przed kolejnymi fascynującymi wyborami, które nadają samochodowi wymiar indywidualny czy wręcz personifikują go. I tak, w przypadku samochodu

${ }^{41}$ I.H. Angus, Circumscribing Postmodern Culture, [w:] Cultural Politics in Contemporary America, red. I.H. Angus, S. Jhally, New York 1989, s. 101-102. 
Focus możemy wybrać jeden z dziesięciu dostępnych kolorów (w tym na przykład Blazer Blue, Mica Shadow Black czy Frozen White), tapicerkę jasną albo ciemną, $\mathrm{w}$ wariancie pięciodrzwiowym, czterodrzwiowym lub kombi, spośród czternastu rodzajów "pojemności skokowej i maksymalnej mocy” oraz niekończących się możliwości w zakresie "komfortu i stylizacji”, "pakietów wyposażenia", "systemów audi i nawigacji” (w każdym z tych przypadków istnieje kilkanaście ofert). Możliwości indywidualizacji są tutaj wprost zdumiewające.

Powracając do problemu płci kulturowej w relacji do samochodu, można stwierdzić, że samochód - potwierdzając dominującą wersję męskości $\mathrm{z}$ drugiej strony stanowi ostateczne zerwanie z esencjalistyczną wizją kobiety zamkniętej w czterech ścianach swojego domowego królestwa - w sferze prywatnej. W pierwszych dekadach $\mathrm{XX}$ wieku kierowanie samochodem przez kobiety stało się „potężnym symbolem równości płciowej” ${ }^{2}$. Amalia Sa'ar i Taghreed Yahia-Younis zwracają jednak w tym kontekście uwagę na fakt, iż o ile w przypadku mężczyzn mamy do czynienia z samochodem jako „inwestycją tożsamościową" (szczególnie w kontekście płci kulturowej), to mimo tego w procesie emancypacji kobiet prowadzenie przez nie samochodu postrzegane jest przede wszystkim $w$ kategoriach funkcjonalnych - jako środek przemieszczania się z miejsca do miejsca ${ }^{43}$. W odniesieniu do kobiety samochód zdaje się stanowić niejako „przedłużenie domu”, pozwala kobiecie efektywniej zrobić zakupy i zawieźć dzieci do szkoły ${ }^{44}$.

Kobieta-kierowca swobodnie przemieszczająca się przez czas i przestrzeń staje się więc najbardziej oczywistym zaprzeczeniem agorafobiczki, u której często jazda samochodem wywołuje uczucie paniki, podobnie jak przebywanie $\mathrm{w}$ tłumie ludzi lub $\mathrm{w}$ ogólne na zewnątrz domu ${ }^{45}$. Kierowanie samochodem stanowi więc $\mathrm{w}$ tym sensie akt emancypacji kobiety, iż wychodzi ona wówczas daleko poza związany z kobiecością stereotyp osoby pasywnej, podporządkowanej, czy za wszelką cenę unikającej niebezpieczeństwa.

Podsumowując moje powyższe rozważania w kwestii relacji między samochodem, tożsamością a płcią kulturową, mogę stwierdzić, iż pełni on tutaj dwojakie funkcje. $Z$ jednej strony potwierdzał on $w$ swojej historii tra-

42 S. O'Connell, The Car and British Society, s. 45.

43 A. Sa'ar, T. Yahia-Younis, Masculinity in Crisis: The Case of Palestinians in Israel, [w:] Gender and Diversity in the Middle East and North Africa, red. Z. Smail Salhi, New York 2010, s. 24.

${ }^{44}$ M. Walsh, Gender and Automoblity, s. 297.

45 W.A. Arrindell i in., Masculinity-femininity as a national characteristic and its relationship with national agoraphobic fear levels: Fodor's sex role hypothesis revitalized, Behaviour Research and Therapy, 2003, 41, s. 796. 
dycyjne dominujące wersje męskości, z drugiej stanowił bez wątpienia źródło emancypacji kobiet. I te funkcje zachowuje również obecnie - niezależnie od tego, że stał się integralnym i naturalnym komponentem codzienności.

\section{BIBLIOGRAFIA}

Angus I.H., Circumscribing Postmodern Culture, [w:] Cultural Politics in Contemporary America, red. I.H. Angus, S. Jhally, New York 1989.

Arrindell W.A., Eisemann M., Richter J., Oei T.P.S., Caballo V.E., van der Ende J., Sanavio E., Bage's N., Feldman L., Torres B., Sica C., Iwawaki S., Hatzichristou Ch., Masculinity-femininity as a national characteristic and its relationship with national agoraphobic fear levels: Fodor's sex role hypothesis revitalized, Behaviour Research and Therapy, 2003, 41.

AutoGuide. com, 2013 Bentley Cars, http://www.autoguide.com/new-cars/bentley, [dostęp: 21.06.2013].

Balkmar D., Drive-by Shaming Reflections on the Emotions of (Dangerous) Car Driving, [w:] Thinking with Beverely Skeggs, red. A. Olsson, Stockholm 2008, http://www. erg.su.se/polopoly_fs/1.39103.1320403015!/Thinking_with_Beverley_Skeggs.pdf.

Barthel D., When Men Put on Appearances. Advertising and the Social Construction of Masculinity, [w:] Man, Masculinity and Media, red. S. Craig, Sage 1992.

Best L.A., Fast Cars, Cool Rides: the Accelerating World of Youth And Their Cars, New York 2006.

Byd F6 commercial ad Cinese Car, spot reklamowy, http://www.youtube.com/ watch?v=1cij9LPNas0, [dostęp: 21.06.2013].

Connell R.W., Arms and the man: using the new research on masculinity to understand violence and promote peace in the contemporary world, [w:] Male roles, masculinities and violence: A culture of peace perspective, red. I. Breines, R. Connell, I. Eide, Paris 2000, May.

Connell R.W., Messerschmidt J.W., Hegemonic Masculinity. Tethinking the Concept, Gender \& Society, 2005, 19.6.

Duda M.B., Traditional Chinese Toggles. Counterweights and Charms, Singapur 2011.

Fiske J., Reading the Popular, London 1994.

Gartman D., Three Ages of Automobile. The Cultural Logics of Car, Theory, Culture and Society, 2004, 21, 69.

Hot'n' Spicy: Paris Hilton's Burger Commercial for Carl's Jr., "A Hamburger Today", May 17, 2005, adres internetowy: http://aht.seriouseats.com/archives/2005/05/hotn-spicy.html; [dostęp: 3.09.2013].

http://www.youtube.com/watch?v=OsxYRJQWc0k, [dostęp: 3.09.2013].

Lipset D., Introduction. Charon's Boat and Other Vehicels of Moral Imagination, [w:] Vehicles: Cars, Canoes and other Metaphors of Moral Imagination, red. D. Lipset, R. Handler, New York-Oxford 2014.

McLaughlin H., Uggen Ch., Blackstone A., Sexual Harassment, Workplace Authority, and the Paradox of Power, American Sociological Review, August 2012, 77, 4 https:// www.soc.umn.edu/ uggen/McLaughlin_Uggen_Blackstone_ASR_12.pdf.

Miruka O., A Training Manual of Masculinities and Engaging Men. To End Gender Based Violence, 2013, https://ke.boell.org/sites/default/files/training_manual_on_mascu linities_and_engaging_men.pdf

O'Connell S., The Car and British Society: Class, Gender and Motoring, 1896-1939. 
Redshaw S., In the Company of Cars. Driving as a Social and Cultural Practice, HampshireBurlington 2008.

Sa' ar A., Yahia-Younis T., Masculinity in Crisis: The Case of Palestinians in Israel, [w:] Gender and Diversity in the Middle East and North Africa, red. Z. Smail Salhi, New York 2010.

Schmid Mast M., Sieverding M., Esslen M., Graber K., Jancke L., Masculinity causes speeding in young men, Accident Analysis and Prevention, 2008, 40.

Schroeder J.E., Zwick D., Mirrors of masculinity: Representation and identity in advertising images, Consumption Markets \& Culture, 2004, 7.1.

Tobin J.J., Re-Made in Japan. Everyday Life and Consumer Taste in a Changing Society, New Haven 1992.

Urry J., Życie za kółkiem, [w:] Socjologia codzienności, red. P. Sztompka, M. BoguniaBorowska, Kraków 2008.

Walsh M., Gender and Automoblity. Selling Cars to American Women after the Second World War, "Charm” 2009, http://learn.quinnipiac.edu/charm/CHARM\%20proceedings/ CHARM\%20article\%20archive\%20pdf\%20format/Volume\%2014\%202009/walsh.pdf

Wernick A., Vehicles for Myth: The Shisfting Image of the Modern Car, [w:] Cultural Politics in Contemporary America, red. I. Angus, S. Jhally, New York 1989.

Xiao Lu P., Elite China: luxury consumer behavior in China, 2011.

Yoo B., Lee S.-H., Buy Genuine Luxury Fashion Products or Counterfeits? Advances in Counsumer Research, 2009, 36. 